\title{
Effect of School-based Oral Health Awareness Lecture on Knowledge, Attitude, and Practice toward Oral Health among Primary School Teachers of Barara, Ambala, Haryana
}

\author{
Mansi Jain ${ }^{1}$, Chaya Chhabra ${ }^{2}$, Hirekanavangala Parvathappa Suma Sogi ${ }^{3}$, Prinka Shahi ${ }^{4}$, Saru Dhir ${ }^{5}$, Swati Rana ${ }^{6}$
}

\begin{abstract}
Aim and objective: To assess the knowledge and its correlation with their attitude and practices regarding oral hygiene and to evaluate the effect of oral health education on their knowledge, attitude, and oral hygiene practices.

Materials and methods: A cross-sectional questionnaire study was conducted on 80 primary school teachers in Barara, District Ambala, Haryana. A self-administered, pretested close-ended questionnaire comprising 20 questions regarding oral health knowledge, attitude, and practice was assessed before and after the dental awareness lecture.

Results: The knowledge of primary school teachers was found to be inappropriate but a statistically highly significant increase in this knowledge with $p$ value $<0.001^{* *}$ after the lecture was observed. With an increase in knowledge, the attitude toward dental health changed with a $p$ value $0.022^{*}$ thus changing their regular dental practices which were when assessed after 15 days, the scores were highly significant with $p$ value $<0.001^{* *}$.

Conclusion: Oral health knowledge was lacking among the primary school teachers though there was a considerable increase in knowledge and change in attitude and practices after the awareness lecture.

Clinical significance: A significant increase in knowledge and change in attitude and oral hygiene practices was observed after the conveyance of the lecture. Thus, arranging for such awareness lectures could be beneficial for controlling oral diseases.

Keywords: Oral health knowledge, Oral health attitude, Oral health practices, Primary school teachers.

World Journal of Dentistry (2021): 10.5005/jp-journals-10015-1842
\end{abstract}

\section{INTRODUCTION}

Oral health is an important component of general health. ${ }^{1}$ The impact of oral disease on people's lives is subtle and pervasive, influencing eating, sleeping, work, and social roles and recurrences of these impacts constitute a silent epidemic. ${ }^{2-4}$ Many different approaches exist to prevent oral diseases, the most cost-effective being the health education delivered in schools. ${ }^{3}$ Oral health promotion through schools is recommended by the World Health Organization, for improving knowledge, attitude, and behavior related to oral health and for prevention and control of dental diseases among school children. ${ }^{1,5}$ Knowledge of oral health is considered to be a prerequisite for health-related behavior. ${ }^{2}$ Childhood is the age where children develop reflexes toward oral hygiene and its practice and the attitude toward health. Children are very susceptible to dental caries and other oral diseases. They depend on their parents and caretakers for their oral health maintenance. ${ }^{6}$ Apart from home, children spend a considerable time in school where they are helped to molds their behavior, attitude, and perceptions toward life. ${ }^{7-9}$ Elementary schools are suitable for imparting oral health information as the children who are potential recipients can be reached at a time when their health habits are developing. . $^{89}$ Teachers can play a vital role in shaping their behavior and overall comprehensive development. ${ }^{7}$ School teachers are more authoritative on children than parents. ${ }^{7}$ The instructions imparted by the teachers are generally followed more sternly by pupils. ${ }^{7}$ Therefore, teachers can be role models for the children and having considerable dental knowledge regarding the development of oral health habits and oral hygiene, they can train their students. ${ }^{8,10}$ Therefore, educating teachers means educating
${ }^{1-6}$ Department of Pediatric and Preventive Dentistry, Maharishi Markandeshwar College of Dental Sciences and Research, Mullana, Haryana, India

Corresponding Author: Mansi Jain, Department of Pediatric and Preventive Dentistry, Maharishi Markandeshwar College of Dental Sciences and Research, Mullana, Haryana, India, Phone: +91 9882600156, e-mail: mansijainsoni@gmail.com

How to cite this article: Jain M, Chhabra C, Suma Sogi HP, et al. Effect of School-based Oral Health Awareness Lecture on Knowledge, Attitude, and Practice toward Oral Health among Primary School Teachers of Barara, Ambala, Haryana. World J Dent 2021;12(4):322-327.

Source of support: Nil

Conflict of interest: None

mothers who then play the role of primary caregivers in the early years of their life. Teachers apart from educating students regarding good oral health can also share knowledge with parents and thus can be helpful to control the progression of early childhood caries as well. Thus, this study was undertaken among school teachers to assess the knowledge and its correlation with their attitude and practices regarding oral hygiene and to evaluate the effect of oral health education on their knowledge, attitude, and oral hygiene practices.

\section{Materials and Methods}

A cross-sectional questionnaire study was conducted by the Department of Pediatric and Preventive Dentistry, Maharishi 
Markandeshwar College of Dental Sciences and Research, Mullana, Ambala, on 80 primary school teachers in Barara, District Ambala, Haryana. Official approval was obtained from the selected schools, and written informed consent was obtained before the study. Participants were assured that their responses would be kept confidential.

\section{Sample Size Estimation}

Barara block of Ambala District has 12 clusters in it consisting of a total number of 156 schools, among which 47 are exclusively primary. We selected one school from each cluster via a lottery system thereby making 12 schools. The total number of primary class teachers in these selected 12 schools was found to be 96 . Among these teachers, 16 were not willing to participate, thus were excluded from the survey. So, sample size came out to be 80 with an $83.33 \%$ response rate.

Barara block has 12 clusters

$$
\downarrow
$$

One school from each cluster via a lottery system

$$
\downarrow
$$

Primary class teachers in 12 schools were 96

$$
\downarrow
$$

16 not willing to participate

$$
\downarrow
$$

$96-16=80$ therefore, $n=80$

$\downarrow$

Response rate $83.33 \%$

A self-structured questionnaire consisting of 20 questions regarding oral health knowledge, attitude, and practice was distributed to these participants. A dental awareness lecture was then delivered by a pediatric dentist followed by a practical demonstration on models about brushing. The same questionnaire was then assessed again after 15 days. The data for all three sections before and 15 days after the lecturer were obtained and analyzed.

\section{Questionnaire Design}

A self-administered, pretested close-ended questionnaire comprising of 20 questions was given to school teachers who were willing to participate. All the questions were in both English and Hindi. The questions consist of information on knowledge, attitude, and practice regarding the maintenance of good oral health. Questions were framed to assess the knowledge $(n=10)$, attitude $(n=5)$, and practice $(n=5)$ regarding oral health. These questions explored the knowledge regarding the primary teeth, oral hygiene measures, dietary habits, and regular dental visits.

\section{Results}

When teachers were assessed for their knowledge on oral health on the basis of various questions, it was observed that their knowledge about the number of milk teeth present in a child's mouth, correct frequency of visiting dentist for a check-up, presence of fluoride in toothpaste, whether milk teeth problems require treatment as it is going to fall, when should be the first dental visit for a child, was inappropriate and statistically highly significant increase in this knowledge with $p$ value $<0.001^{* *}$ after the lecture was observed (Table 1 and Fig. 1).

With an increase in knowledge, the attitude toward dental health changed with a $p$ value $0.022^{*}$ thus changing their regular dental practices. The frequency of toothbrushing increased with adopting the habit of brushing twice daily in the morning and
Table 1: Comparison of mean knowledge, attitude, and practice scores pre- and post-conveyance of the lecture

\begin{tabular}{llll}
\hline Domain & $\begin{array}{l}\text { Pre-test mean } \\
\text { value }\end{array}$ & $\begin{array}{l}\text { Post-test mean } \\
\text { value }\end{array}$ & pvalue \\
\hline Knowledge & $8.11 \pm 1.17$ & $9.05 \pm 1.12$ & $<0.001^{* *}$ \\
Attitude & $1.86 \pm 0.77$ & $2.15 \pm 0.82$ & $0.022^{*}$ \\
Practice & $2.63 \pm 0.97$ & $3.43 \pm 0.93$ & $<0.001^{* *}$ \\
\hline
\end{tabular}

*Significant

**Highly significant

evening with the right amount of toothpaste and enough time spend brushing a child's teeth. When practice was assessed after 15 days, the scores were highly significant with a $p$ value $<0.001^{* *}$ (Table 1 and Fig. 2).

\section{Discussion}

Oral diseases like other diseases such as diabetes, hypertension, and cardiac problems often affect the general well-being of a person but still, they are overlooked due to lack of knowledge about oral health, thus making them chronic, painful, and disfiguring. They restrict activities at work and home. ${ }^{11,12}$ Moreover, the psychosocial impact of these diseases often significantly diminishes the quality of life creating a huge economic and social burden if not taken care of timely. ${ }^{11}$ Oral health education can be beneficial to improve knowledge leading to the adoption of favorable oral health practices. To impart knowledge and the adoption of good oral practices right from childhood, teachers can play a pivotal role. Awareness lectures on oral health should be encouraged to be included in teaching programs, school activities, and regular school curriculum to have the benefit of continuity in education., ${ }^{70,13}$ School curriculum should be exciting and stimulating for students to acquire good oral health knowledge and behavior. ${ }^{7}$

As teachers are often considered role models by students and can easily reach all the children, ${ }^{8}$ their involvement in school health education and health promotion holds an important place in many ways. ${ }^{7,13}$ Oral hygiene instructions can be reinforced at times due to the continuous availability of children and teachers, demonstration of brushing technique can be integrated with other activities, and overall low costs associated with such programs make it more practical. ${ }^{10}$ Moreover, a teacher may assess the child's performance frequently and encourage them to improve further. ${ }^{10}$ But, lack of proper teacher training may be a significant barrier to the success of health-promoting school programs. ${ }^{13}$

In the present study, when knowledge was assessed most of the teachers agreed that oral health is as important as our general health but proper knowledge of how to take care of oral health was missing. Only $70 \%$ of people were aware of the exact number of deciduous teeth present in the oral cavity. There was a highly significant increase to $100 \%$ in this knowledge with $p$ value $<0.0001^{* * *}$, after delivery of lecture (Table 2 and Fig. 1). The majority of people (97.5\%) cited that sticky food and sugar can cause tooth decay and $98.8 \%$ agreed child's teeth should be checked regularly by a dentist but they responded inconsistently about how frequently and at what age they should visit the dentist (Table 2 and Fig. 1). As the oral importance was understood after health education lecture, a highly significant increase up to $87.5 \%$ with $p$ value $<0.0001^{* * *}$, was there about awareness of visiting dentist, for regular dental examination of milk teeth which should be once in every 3 months whereas initially, only $36.3 \%$ were aware (Table 2 and Fig. 1). Before $76.3 \%$ of respondents knew that the 


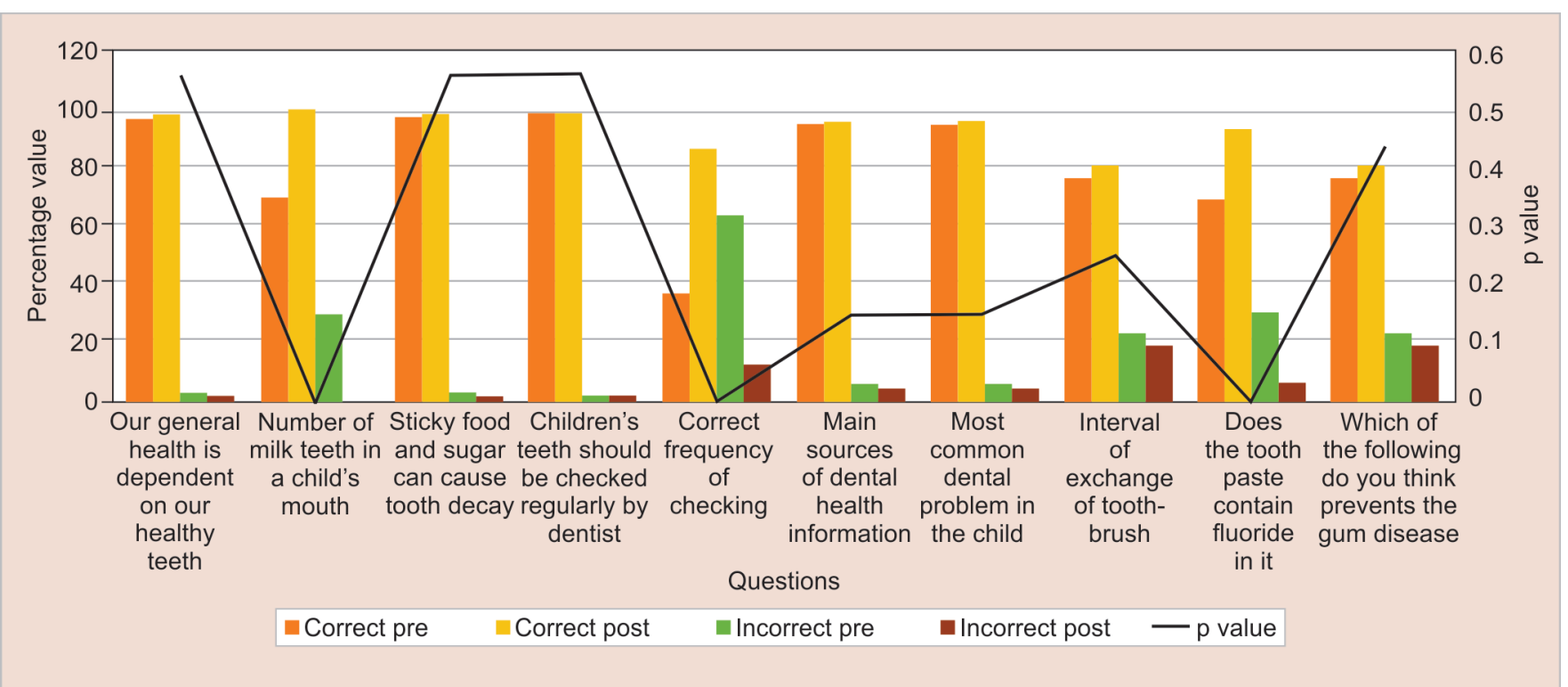

Fig. 1: Distribution of responses on knowledge-pre- and post-conveyance of lecture

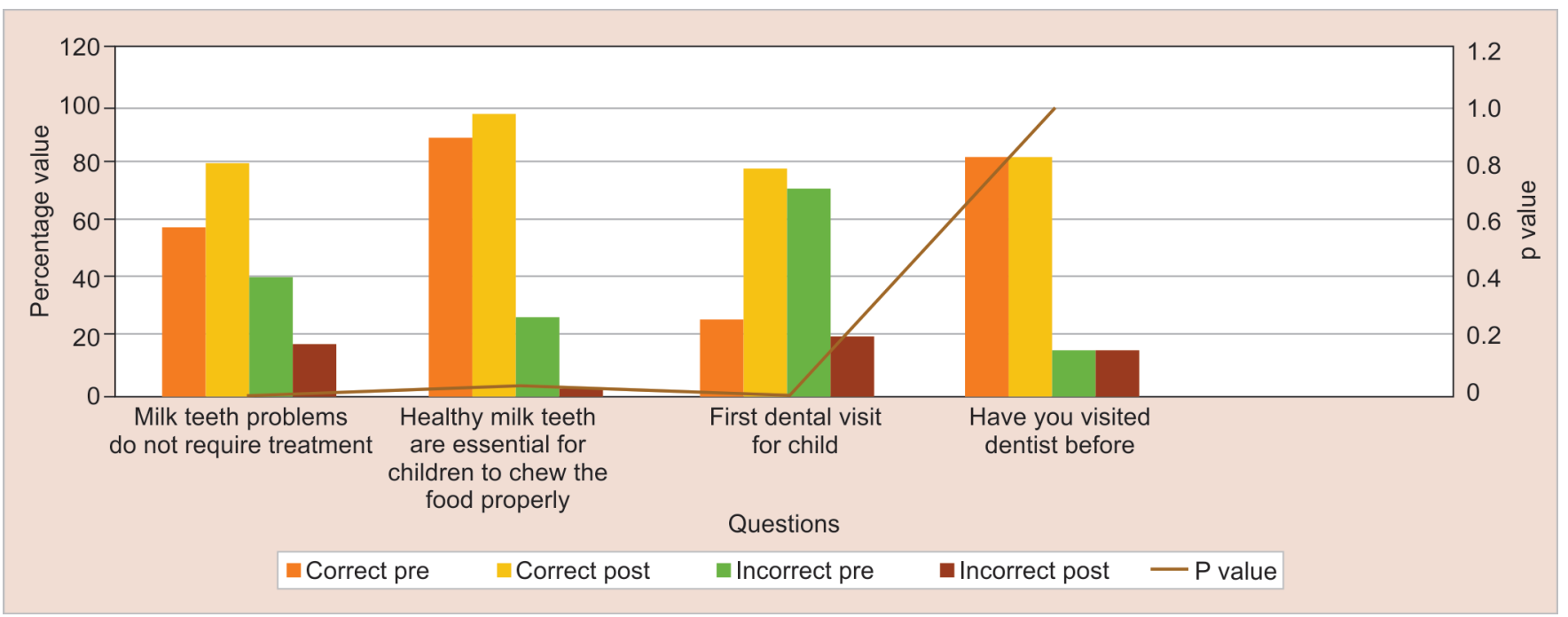

Fig. 2: Distribution of responses on attitude-pre- and post-conveyance of lecture

interval of exchange of toothbrush should be 3 months but the awareness increased, though not significantly, to $81.3 \%$ after the lecture (Table 2 and Fig. 1). Knowledge regarding the presence of fluoride in the toothpaste was also found lacking (68.8\%) which was improved to $93.8 \%$ with a $p$ value $<0.0001^{* * *}$ which was highly significant, after explaining the benefits of fluorides on dental health (Table 2 and Fig. 1). 81.3\% agreed that regular brushing, use of mouth wash as well as cleaning by a dentist prevents gum disease, whereas initially, $76.3 \%$ had the opinion that regular brushing and use of mouth wash is enough (Table 2 and Fig. 1).

In attitude toward oral health, it was observed that only $58.8 \%$ of teachers disagreed that milk teeth problems do not require treatment as it is going to fall anyway and this score increased significantly to $81.25 \%$ with a $p$ value $0.001^{*}$, as the knowledge increased so the attitude toward saving the milk teeth also changed. $90 \%$ already believed that healthy milk teeth are essential for children to chew the food properly. This attitude increased further to $97.5 \%$ after the awareness lecture (Table 3 and Fig. 2). To the question regarding the previous visit to the dentist, $83.8 \%$ of the respondents had visited a dentist earlier. Of those, $40 \%$ visited for restorations, $20 \%$ due to dental pain, $30 \%$ for extraction, and only $10 \%$ for oral prophylaxis (Table 3 and Fig. 2). This figure thereby suggests that a very small number visited for preventive procedures as their awareness about oral health is lacking. Attitude toward the first dental visit of the child also significantly improved with a $p$ value $<0.0001^{* *}$. $78.8 \%$ of people agreed that the correct age to visit the dentist for a first dental check-up is 6-12 months as they were told that the first deciduous tooth erupts by this age, whereas previously only $27.5 \%$ of people knew the correct age (Table 3 and Fig. 2). Thus, it was comprehended that the overall attitude toward the importance of oral health improved when oral health education was imparted.

As practice was evaluated most of the parents (83.8\%) used toothpaste only, for brushing the child's teeth (Table 4 and Fig. 3). 
Table 2: Distribution of responses on knowledge-pre- and post-conveyance of lecture

\begin{tabular}{|c|c|c|c|c|}
\hline Knowledge questions & Time & Correct n (\%) & Incorrect n (\%) & p value \\
\hline \multirow[t]{2}{*}{ 1. Our general health is dependent on our healthy teeth } & Pre & $78(97.5)$ & $2(2.5)$ & $0.560 \mathrm{NS}$ \\
\hline & Post & $79(98.8)$ & $1(1.2)$ & \\
\hline \multirow[t]{2}{*}{ 2. Number of milk teeth in a child's mouth } & Pre & $56(70)$ & $24(30)$ & $<0.0001^{* *}$ \\
\hline & Post & $80(100)$ & $0(0)$ & \\
\hline \multirow[t]{2}{*}{ 3. Sticky food and sugar can cause tooth decay } & Pre & $78(97.5)$ & $2(2.5)$ & $0.560 \mathrm{NS}$ \\
\hline & Post & $79(98.8)$ & $1(1.2)$ & \\
\hline \multirow[t]{2}{*}{ 4. Children's teeth should be checked regularly by dentist } & Pre & $79(98.8)$ & $1(1.2)$ & $0.506 \mathrm{NS}$ \\
\hline & Post & $79(98.8)$ & $1(1.2)$ & \\
\hline \multirow[t]{2}{*}{ 5. Correct frequency of checking } & Pre & $29(36.3)$ & $51(63.7)$ & $<0.0001^{* *}$ \\
\hline & Post & $70(87.5)$ & $10(12.5)$ & \\
\hline \multirow[t]{2}{*}{ 6. Main sources of dental health information } & Pre & $76(95)$ & $4(5)$ & 0.149 NS \\
\hline & Post & $77(96.3)$ & $3(3.7)$ & \\
\hline \multirow[t]{2}{*}{ 7. Most common dental problem in the child } & Pre & $76(95)$ & $4(5)$ & 0.149 NS \\
\hline & Post & $77(96.3)$ & $3(3.7)$ & \\
\hline \multirow[t]{2}{*}{ 8. Interval of exchange of toothbrush } & Pre & $61(76.3)$ & $19(23.7)$ & $0.249 \mathrm{NS}$ \\
\hline & Post & $65(81.3)$ & $15(18.7)$ & \\
\hline \multirow[t]{2}{*}{ 9. Does the toothpaste contain fluoride in it } & Pre & $55(68.8)$ & $25(31.2)$ & $<0.0001^{* *}$ \\
\hline & Post & $75(93.8)$ & $5(6.2)$ & \\
\hline \multirow[t]{2}{*}{ 10. Which of the following do you think prevents the gum disease } & Pre & $61(76.3)$ & $19(23.7)$ & 0.439 NS \\
\hline & Post & $65(81.3)$ & $15(18.7)$ & \\
\hline
\end{tabular}

**Highly significant

Table 3: Distribution of responses on attitude-pre- and post-conveyance of lecture

\begin{tabular}{|c|c|c|c|c|}
\hline Attitude questions & Time & Correct n (\%) & Incorrect n (\%) & \\
\hline \multirow{2}{*}{$\begin{array}{l}\text { 11. Milk teeth problems do not require treatment as they going to } \\
\text { fall anyway }\end{array}$} & Pre & $47(58.8)$ & $33(41.2)$ & $0.001^{*}$ \\
\hline & Post & $65(81.25)$ & 15 (18.75) & \\
\hline \multirow{2}{*}{$\begin{array}{l}\text { 12. Healthy milk teeth are essential for children to chew the food } \\
\text { properly }\end{array}$} & Pre & $72(90)$ & $8(28)$ & $0.050 \mathrm{NS}$ \\
\hline & Post & $78(97.5)$ & $2(2.5)$ & \\
\hline \multirow[t]{2}{*}{ 13. First dental visit for child } & Pre & $22(27.5)$ & $58(72.5)$ & $<0.0001^{* *}$ \\
\hline & Post & $63(78.8)$ & $17(21.2)$ & \\
\hline \multirow[t]{2}{*}{ 14. Have you visited a dentist before } & Pre & $67(83.8)$ & $13(16.2)$ & $1 \mathrm{NS}$ \\
\hline & Post & $67(83.8)$ & $13(16.2)$ & \\
\hline \multirow[t]{4}{*}{ 15. Reasons for visiting dentist before } & Pre & (a) Cleaning - 10 & (a) Cleaning - 10 & $1 \mathrm{NS}$ \\
\hline & & (b) Pain-20\% & (b) Pain-20\% & \\
\hline & & (c) Tooth filling-40\% & (c) Tooth filling- $40 \%$ & \\
\hline & & (d) Removal-30\% & (d) Removal-30\% & \\
\hline
\end{tabular}

*Significant

**Highly significant

Initially, $56.25 \%$ of parents use to brush their teeth only once, in the morning but after the lecture, $87.5 \%$ adapted to the habit of brushing twice daily. The figures were highly significant with a $p$ value being $<0.0001^{* *}$ (Table 4 and Fig. 3). Parents believed that it is the amount of toothpaste that is going to clean the tooth and there forth $92.5 \%$ used large amount. After the lecture, 56.25\% adopted the habit of using only pea-size toothpaste for children up to the age of 3 years. The figures were again highly significant with a $p$ value being $<0.0001^{* *}$ (Table 4 and Fig. 3). $86.3 \%$ responded that they spend enough time that is $>3$ minutes for brushing to allow for proper cleaning, which further increased significantly to $96.3 \%$ after the lecture with $p$ value being $0.025^{*}$ (Table 4 and Fig. 3 ).

Therefore, a considerable increase in knowledge, attitude, and practice was noticed before and after the lecture. A statistically highly significant score was observed among knowledge ( $p$ value $<0.001^{* * *}$ ) and practice ( $p$ value $<0.001^{* *}$ ), whereas for attitude ( $p$ value $0.022^{* *}$ ), the scores were statistically significant before and after imparting oral health education (Table 1 and Fig. 4).

Lack of resources, lack of time, and failure to incorporate oral health into the curriculum have been implicated as major barriers to teaching oral health in schools. ${ }^{13}$ Teacher's knowledge regarding oral diseases and conditions is also inappropriate and the majority of teachers had not received any formal training on oral health education and knowledge. ${ }^{13}$ Therefore, arranging for such training and awareness programs for teachers is beneficial as oral health education is effective in improving the knowledge attitude and practice of oral health and in reducing plaque, bleeding on probing of the gingiva and caries increment. ${ }^{14}$ As teachers can influence 
Table 4: Distribution of responses on practice-pre- and post-conveyance of lecture

\begin{tabular}{|c|c|c|c|c|}
\hline Practice questions & Time & Correct n (\%) & Incorrect n (\%) & \\
\hline \multirow[t]{2}{*}{ 16. Material used to clean your child's teeth } & Pre & $67(83.8 \%)$ & $13(16.2 \%)$ & 0.499 NS \\
\hline & Post & $70(87.5 \%)$ & $10(12.5 \%)$ & \\
\hline \multirow[t]{2}{*}{ 17. Frequency of toothbrushing } & Pre & $45(56.25 \%)$ & $35(43.75 \%)$ & $<0.0001^{* *}$ \\
\hline & Post & $70(87.5 \%)$ & $10(12.5 \%)$ & \\
\hline \multirow[t]{2}{*}{ 18. Time of toothbrushing } & Pre & $32(40 \%)$ & $48(60 \%)$ & $0.004^{*}$ \\
\hline & Post & $50(62.5 \%)$ & $30(37.5 \%)$ & \\
\hline \multirow[t]{2}{*}{ 19. Toothpaste amount used to brush a child's teeth } & Pre & $6(7.5 \%)$ & $74(92.5 \%)$ & $<0.0001^{* *}$ \\
\hline & Post & $45(56.25 \%)$ & $35(43.75 \%)$ & \\
\hline \multirow[t]{2}{*}{ 20. Time spent on brushing teeth } & Pre & $69(86.3 \%)$ & $11(13.7 \%)$ & $0.025^{*}$ \\
\hline & Post & 77 (96.3\%) & $3(3.7 \%)$ & \\
\hline
\end{tabular}

*Significant

**Highly significant

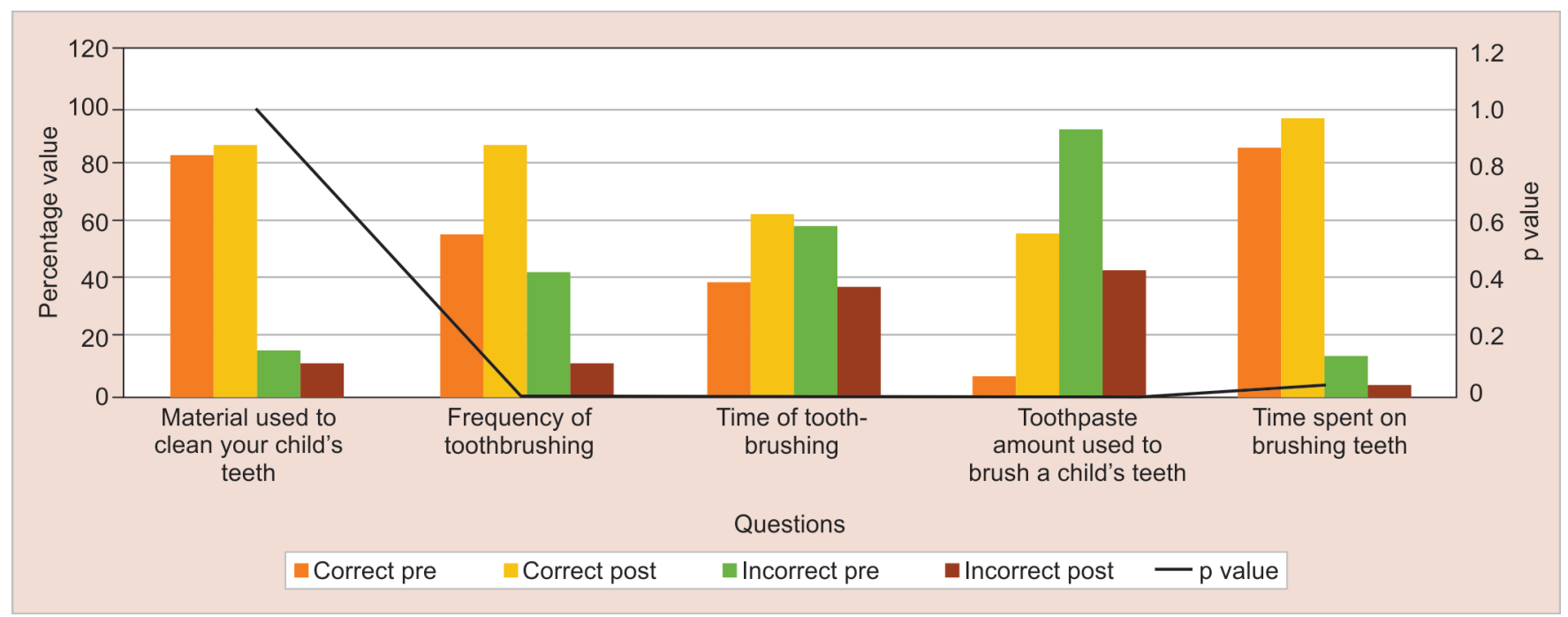

Fig. 3: Distribution of responses on practice-pre- and post-conveyance of lecture

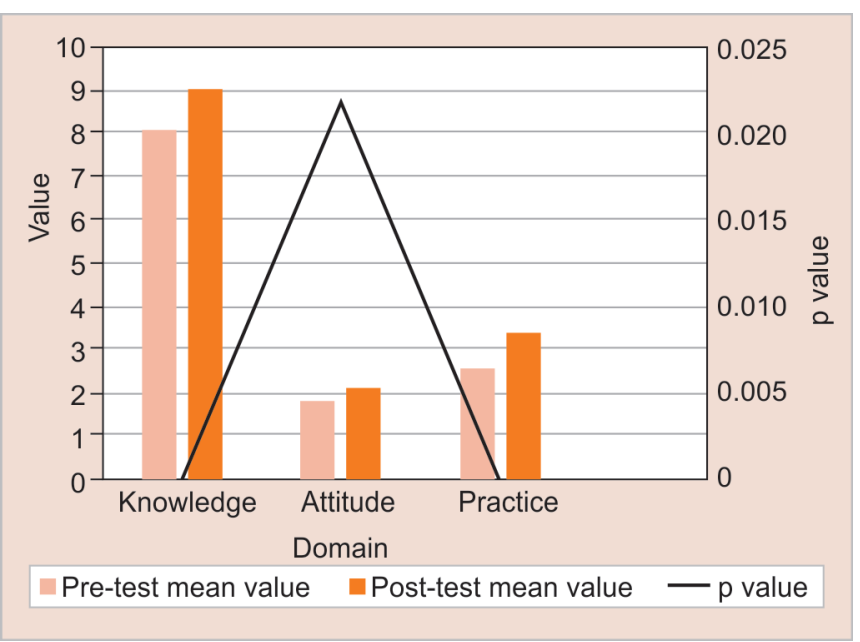

Fig. 4: Comparison of mean knowledge, attitude, and practice scores pre- and post-conveyance of lecture

large numbers of children and their parents, they can play an important role in developing healthy habits in their students and acts as significant alternative personnel in the struggle to prevent oral diseases. $^{15}$

\section{Conclusion}

Teachers have a moral responsibility of ensuring the child's health and safety. To achieve this, teachers need to have sound knowledge regarding general and oral health. The findings of the present study indicate that oral health knowledge was lacking among the primary school teachers, though there was a considerable increase in knowledge and change in attitude and practices after the awareness lecture. Arranging for such teacher training programs that include oral health knowledge and approaches to dental health education within school setting could be beneficial for training teachers to make dental care available at an early age and follow oral hygiene practices in young growing population which makes the major future of tomorrow.

\section{Clinical Significance}

After the conveyance of the lecture, a significant increase in knowledge and change in attitude and oral hygiene practices was observed. Thus, arranging for such awareness lectures could be beneficial for controlling oral diseases.

\section{Ethical Statement}

Ethical approval to conduct the study was obtained from the Institutional ethical committee via project number 1733. 


\section{References}

1. Mehta A, Kaur G. Oral health related knowledge, attitude and practices among 12 years old school children studying in rural areas of Panchkula, India. Indian J Dent Res 2012;23(1):2. DOI: 10.4103/09709290.99028.

2. Aggnur M, Garg S, Veeresha KL, et al. Oral health status, treatment needs and knowledge, attitude and practice of health care workers of Ambala, India - A cross sectional study. Ann Med Health Sci Res 2014;4:5.

3. Haque SE, Rahman M, Itsuko K, et al. Effect of a school-based oral health education in preventing untreated dental caries and increasing knowledge, attitude, and practices among adolescents in Bangladesh. BMC Oral Health 2016;16(1):44. DOI: 10.1186/s12903016-0202-3.

4. Onwudi HI, Taiwo AO, Stellamaris OC. Oral health knowledge, attitude, and practices among secondary school teachers and students in Ekiti State. Niger J Exp Clin Biosci 2017;5(1):16-24. DOI: 10.4103/njecp. njecp_34_15.

5. Peterson PE. World Health Organization global policy for improvement of oral health. Int Dent J 2008;58(3):115-121. DOI: 10.1111/j.1875-595X.2008.tb00185.x.

6. Krishnan L, Prabha G, Madankumar PD. Knowledge, attitude, and practice about oral health among mothers of children with special needs - A cross-sectional study. J Dent Res Rev 2019;6(2):39-43. DOI: 10.4103/jdrr.jdrr_21_19.

7. Amith HV, Madonna D'Cruz A, Shirahatti RV. Knowledge, attitude and practice regarding oral health among the rural government primary school teachers of Mangalore, India. J Dent Hygie 2013;87:6.
8. Sekhar V, Sivsankar P, Easwaran MA, et al. Knowledge, attitude and practice of school teachers towards oral health in Pondicherry. J Clin Diagnos Res 2014;8(8):ZC12-ZC15. DOI: 10.7860/JCDR/2014/ 9779.4676.

9. Blaggana A, Grover V, Anjali, et al. Oral health knowledge, attitudes and practice behaviour among secondary school children in Chandigarh. J Clin Diagnos Res 2016;10(10):ZC01-ZC06.

10. Mota A, Oswal KC, Sajnani DA, et al. Oral health knowledge, attitude, and approaches of pre-primary and primary school teachers in Mumbai, India. Hindawi Publishing Corporation Scientifica 2016. 8.

11. Gambhir RS, Sohi RK, Nanda T, et al. Impact of school based oral health education programmes in India: a systematic review. J Clin Diagn Res 2013;7(12):3107-3110. DOI: 10.7860/JCDR/2013/ 6212.3718.

12. Al Subait AA, Alousaimi M, Geeverghese A, et al. Oral health knowledge, attitude and behavior among students of age 10-18 years old attending Jenadriyah festival Riyadh. A cross-sectional study. Saudi J Dent Res 2016;7(1):45-50. DOI: 10.1016/j.sjdr.2015.05.001.

13. Ramroop V, Wright D, Naidu R. Dental health knowledge and attitudes of primary school teachers toward developing dental health education. West Indian Med J 2011;60(5):576.

14. Nakre PD, Harikiran AG. Effectiveness of oral health education programs: a systematic review. J Int Soc Prev Community Dent 2013;3(2):103-115. DOI: 10.4103/2231-0762.127810.

15. Maganur PC, Satish V, Marwah N, et al. Knowledge, attitudes, and practices of school teachers toward oral health in davangere, India. Int J Clin Pediatr Dent 2017;10(1):89-95. DOI: 10.5005/ jp-journals-10005-1413. 